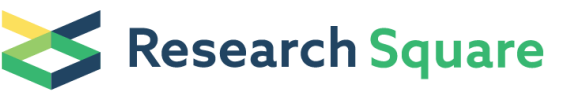

Preprints are preliminary reports that have not undergone peer review.

They should not be considered conclusive, used to inform clinical practice, or referenced by the media as validated information.

\section{Implementation of a Complex Health Services Intervention in Long-term Care Homes: A Process Evaluation Using Focus Groups}

\section{Rieka von der Warth ( $\nabla$ rieka.warth@uniklinik-freiburg.de )}

Section of Health Care Research and Rehabilitation Research, Medical Center - University of Freiburg, Faculty of Medicine, University of Freiburg, Freiburg, Germany https://orcid.org/0000-0003-2445-8019

\section{Vanessa Kaiser}

Section of Health Care Research and Rehabilitation Research, Medical Center - University of Freiburg, Faculty of Medicine, University of Freiburg, Freiburg, Germany

\section{Christina Reese}

Section of Health Care Research and Rehabilitation Research, Medical Center - University of Freiburg, Faculty of Medicine, University of Freiburg, Freiburg, Germany

\section{Boris A. Brühmann}

Section of Health Care Research and Rehabilitation Research, Medical Center - University of Freiburg, Faculty of Medicine, University of Freiburg, Freiburg, Germany

\section{Erik Farin-Glattacker}

Section of Health Care Research and Rehabilitation Research, Medical Center - University of Freiburg, Faculty of Medicine, University of Freiburg, Freiburg, Germany

\section{Research article}

Keywords: process evaluation, nursing homes, focus groups, qualitative study, coordinated medical care, elderly, primary care, complex health intervention, implementation research

Posted Date: August 6th, 2020

DOI: https://doi.org/10.21203/rs.3.rs-46877/v1

License: (c) (i) This work is licensed under a Creative Commons Attribution 4.0 International License. Read Full License 


\section{Abstract}

\section{Background}

With increasing numbers of the elderly living in nursing homes in Germany, the need for on-site primary care increases. A lack of primary care in nursing homes can lead to unnecessary hospitalization, higher mortality, and morbidity in the elderly. Therefore, project CoCare ("coordinated medical care") implements a complex health intervention in nursing homes, using among others regular medical rounds, a shared patient medical record and medication checks, aiming to improve the coordination of medical care. This study reports the results of a process evaluation assessing the perceived acceptance and barriers of the project by stakeholders.

\section{Methods}

Focus group interviews were held between the fall of 2018 and the fall of 2019 with nursing staff, general practitioners and medical assistants working in or consulting a participating nursing home. A halfstructured modular guideline was used to ask participants about their opinion on different aspects of CoCare. Focus groups were analyzed using qualitative content analysis.

\section{Results}

In total, $\mathrm{N}=11$ focus group interviews with $\mathrm{N}=\mathbf{7 4}$ participants were conducted. Ten main themes with seven subthemes were identified, encompassing all aspects of CoCare. The overall acceptance of the project was good. Participants elected to talk most often about the project modules "communication and collaboration" and "medical rounds", with participants concluding CoCare had prevented unnecessary hospitalizations. Main barriers were understaffing and complexity of the program.

\section{Conclusion}

Implementation of CoCare in nursing homes is complex and holds some barriers. However, the overall acceptance was good and first positive results were reported by participants. Furthermore, the project provides a good structure to overcome potential barriers.

Trial Registration: German Clinical Trial Register (DRKS00012703)

\section{Background}

Demographic transition is in full swing in Germany, with every fifth person being over 66 years old (1). About two million people in Germany are in need of long-term care (2) and care provided in nursing homes (NHs) is seen as appropriate (3). Thus, in 2018, approximately 700.000 people were already living in $\mathrm{NHs}$ in Germany (2). 
Overall, higher age was shown to be associated with higher health care utilization compared to the general population $(4,5)$. Yet, the level of care needed was negatively associated with the probability of utilizing medical specialists, showing inequality in health care system (6). Other reports show a lack of primary care in $\mathrm{NHs}$ (7), leading to unnecessary hospitalizations for the elderly (8-10). Unnecessary hospital admissions were not only shown to be costly $(9,11)$, but also increased the risk of complications and mortality in $\mathrm{NH}$ residents $(12,13)$. The insufficient availability of general practitioners (GPs) and acute care were determined to be the main reasons for unnecessary admissions to the hospital in several studies $(9,14)$. However, the implementation of primary care in NHs is hindered by the lack of infrastructure or insufficient compensation of physicians. Project CoCare ("coordinated medical care") aims to bridge the gap by implementing a complex health care intervention to improve primary care in $\mathrm{NHs}$ (15). The study takes place in the federal state of Baden-Wuerttemberg, Germany, with $31 \mathrm{NHs}$ implementing the new intervention, providing it to approximately 1,150 residents. Furthermore, $25 \mathrm{NHs}$ providing survey data will be used as control group and additionally claims data of $\mathrm{N}=8,000$ of $\mathrm{NH}$ residents in Baden-Wurttemberg will be randomly drawn for comparison. Among others, the intervention provides a shared patient medical record called CoCare Cockpit (CCC) and standard courses of treatment for NH staff and consulting GPs. Furthermore, it compensates weekly on-site medical rounds, regular medication checks, case conferences and extended availability of GPs. CoCare also aims at improving communication and collaboration between GPs and nurses by forming teams of physicians sharing care duties and by appointing a CoCare contact person in every $\mathrm{NH}$. As results, an increase in quality of care, care efficiency as well as a reduction in costs are expected. See Figure 1 for an overview of all modules of the project. Further information on the project and its study design has been published elsewhere: Brühmann, Reese (15).

In accordance with the guidelines for complex services interventions by Moore, Audrey (16), a formative process evaluation is conducted for this project. Acquiring specific information on the implementation process is crucial for decision makers before implementing the intervention on a larger scale. A process evaluation will therefore investigate how a complex health intervention is delivered and how the fidelity for the intervention is $(17,18)$.

This paper describes the results of the qualitative process evaluation for project CoCare that were obtained using focus group interviews investigating the acceptance of the intervention by stakeholders and the barriers for implementation.

\section{Methods}

This research was funded by the Innovation Committee at the Federal Joint Committee (G-BA), Germany under grant number NVF1_2016-080. The process evaluation was conducted at the Medical Center University of Freiburg. Ethical approval for this study was granted by the Ethics Committee of the University of Freiburg (Approval Number: 333/17). The study was registered at the German Clinical Trial Register (DRKS00012703). Results are reported complying with the Consolidated criteria for reporting qualitative research (COREQ) checklist (19). 


\section{Study Design}

Participants were GPs, nursing staff and medical assistants working in or consulting a NH enrolled in CoCare. Focus groups were conducted between fall of 2018 and 2019. Participation was voluntary and no disadvantages arose from non-participation. Participants were supplied with information on the aim of the focus group interviews and written informed consent was obtained from all participants. As the project team used various methods for the process evaluation (15), some of the participants and researchers knew each other from previous contacts.

Focus groups were conducted using a half-structured modular guideline, assessing the opinion of participants towards the different aspects of the project (see Brühmann, Reese (15) for a description of the project). A modular guideline was chosen as CoCare comprises many modules and using a modular guideline, participants were able to pick which of the many aspects within the intervention were particularly important to discuss. The interview guideline was developed for this study by the authors based on the study design of CoCare (15) and the expertise of the scientists (see Additional File 1). The interview guideline was also previously published in Brühmann, Reese (15).

After a short introduction by the researcher, participants received a set of predetermined discussion topics to choose from. The researcher then asked open questions about the topics chosen to inquire about implementation progress and barriers.

Focus groups were conducted by $\mathrm{CR}$ and $\mathrm{BB}$ within the NHs. All focus groups were digitally recorded and transcribed verbatim by an external service provider. The transcripts were pseudonymized and given a consecutive ID-Number from 1 to 11. As the focus groups were held in German, participant's quotes to illustrate the finding were translated into English by the authors of this manuscript.

\section{Data analysis}

Data analysis was based on the content analysis outlined by Mayring (20). For this purpose, an initial coding system was developed based on the modules from the modular guideline. VK and RvdW then analyzed the first three interviews independently, using the initial coding system and taking notes as necessary. The results were discussed by VK and RvdW, adapting the coding system to the findings. This process was repeated twice before generating the final coding system (see Table 1). RvdW then coded the remaining focus groups using the final coding system. The results were presented to and discussed at different stages of the data analysis with the project team to ensure intersubjective comprehensibility. Data management was done using MAXQDA 2020 (21).

Table 1: Main themes and subthemes 


\begin{tabular}{|ll|}
\hline Main themes & Subthemes \\
\hline State of implementation & Barriers for implementation \\
\hline CoCare-Cockpit & Management of catheters \\
\hline & Use of the CoCare-Cockpit \\
\hline & Benefits \\
\hline Medical rounds & Barriers of use \\
\hline Medication check & Double documentation \\
\hline Communication and collaboration & \\
\hline Medical specialists & General practitioner teams \\
\hline Extended accessibility & \\
\hline Case conferences, quarterly and year meetings & \\
\hline Standard courses of treatment & \\
\hline Overall assessment
\end{tabular}

\section{Researcher characteristics}

RvdW is a female researcher in the field of health services research and rehabilitation research. She holds a degree in psychology and has experience with qualitative studies. VK is a female master student in psychology and works as a student assistant in the field of health services research. Both, CR and BB are postdoctoral researchers in the field of health services research and rehabilitation research. $\mathrm{CR}$ is a trained psychologist, and BB holds two degrees in health sciences. EF is a full time professor in health services research and rehabilitations research. His work focuses on methods in health services research.

\section{Results}

\section{Participants}

$\mathrm{N}=11$ focus groups with a total of $\mathrm{N}=74$ participants were conducted. $78.8 \%$ of all participants were female. Most of the participants were nurses working within the participating $\mathrm{NHs}(\mathrm{n}=48)$, followed by consulting GPs $(n=20)$. A full overview of the distribution of participants can be seen in Table 2. As CoCare focuses on the medical team as a whole, differences between professions were not analyzed. 


\begin{tabular}{|llll|}
\hline & Male & Female & Total \\
\hline General practitioners & 13 & 7 & 20 \\
\hline Medical assistants & 0 & 6 & 6 \\
\hline Nursing staff & 3 & 45 & 48 \\
\hline Total & 16 & 58 & 74 \\
\hline
\end{tabular}

\section{CoCare}

Participants had opinions and associations regarding all aspects of CoCare, thus ten main themes (see Table 1) were found: state of implementation; CCC (electronic medical record); medical rounds; medication check; communication and collaboration; medical specialists; extended availability; case conferences, quarterly and yearly meetings; treatment courses; overall assessment. Furthermore, seven subthemes were identified. An overview of all main and subthemes including descriptions and coding rules can be found in the Additional File 2.

\section{State of implementation}

Because NHs entered the project at different times, the state of implementation differed across facilities. According to the participants, the biggest barrier for full implementation was the lack of available resources to devote to the intervention, like nursing staff's time. The issue of understaffing due to sickness or training was repeatedly mentioned.

However, even if single components had not yet been implemented in the NHs, participants emphasized that CoCare builds awareness for the health care of the elderly.

"It would be possible during normal business. But then? Someone gets sick, someone is absent, someone is in training. And suddenly no one is here or no one, who can....no one has time to do these additional tasks." (Focus group 1)

"State of implementation" included the following subthemes: management of suprapubic catheters; barriers for implementation.

\section{CoCare-Cockpit (CCC)}

Participants had varying opinions on the CCC (electronic medical records). Overall, the idea of common electronic medical records between GPs and NH was rated positively. Improved preparation of medical rounds and automated treatment recommendations were named as positive aspects of CCC. However, 
many $\mathrm{NHs}$ struggled to make regular use of $\mathrm{CCC}$, as regulatory standards require separate documentation of the provided care in addition to any records made in CCC. The resulting double documentation might lead to mistakes.

"And if you ask me, that would lead to mistakes, because every normal person, when they have written or typed the exact same thing for the third time, they would leave something out, no longer want to...(several other participants agree in the background)... every normal person would do that....( Focus group 11)

The main theme "CoCare-Cockpit (CCC)" included the subthemes: use of CoCare-Cockpit; benefits; barriers of use; double documentation.

\section{Medical rounds}

According to the participants, the newly implemented weekly medical rounds attended by GPs and nursing staff were one of the most important modules of CoCare. Even though some NHs had regular medical rounds before the project, but most participants reported positive effects. Holding rounds on the same day each week allowed for better preparation by both nursing staff and GPs. If GPs worked in a team at a $\mathrm{NH}$, they would leave a message for the GP to lead the next visits. This way a continuous treatment of residents could be guaranteed. According to some participants, residents would feel much more comfortable since medical rounds were scheduled regularly. One participant said that the newly implemented GP's visits were already preventing unnecessary hospitalizations.

„....due to these visits, I know all the patients, know their pathology [...] and I would say, that we notice,... even skin changes or the patient has a little fever or something alike, so we can really prevent hospitalizations." (Focus group 7)

\section{Medication check}

In most NHs, medication checks are conducted during medical rounds. Participants stressed the importance of the medication checks, as some residents had been given a lot of medication. They valued that the project reminded them to conduct the medication checks regularly.

Medication checks were especially important after a hospital discharge, as hospital doctors would not pay attention to existing medication, changing the medication plan or adding new medication.

Additionally, participants wished that the CCC would give a warning if two or more medications had negative interaction effects.

But now, sitting down during the visits, looking at the medication plan together and talking about it with every professional. [...] Most medications are from the hospital, stay in the plan or will be continued to be given. [...] (Focus group 9) 


\section{Communication and collaboration}

The project was seen as a team building intervention by many participants. Communication and collaboration are very important in $\mathrm{NHs}$ and CoCare might have led to more trust within the team. Due to the strict framework of the project more time for communication and consultations is left.

For nursing staff, the barriers to talk to GPs were lowered, making it easier to agree on a resident's treatment. Participants said teamwork was more professional in some NHs now and decisions were being made with the whole team involved. Also, participants regarded a consistent contact person within the $\mathrm{NHs}$ as positive.

GPs appreciated the newly built general pracitioners' teams to consult a $\mathrm{NH}$, as visits and treatment planning would be easier now.

Again, one participant mentioned that the improved communication within the team had already led to a prevention of unnecessary hospitalizations.

"When I come here, I have a number I can dial, I have someone who has time for me and is my contact person. And I need to say: There is some structure. When something is not clear, there is someone I can talk to." (Focus group 2)

The theme "Communication and collaboration" includes the subtheme: general practitioner teams

\section{Medical specialists}

All participants were of the opinion that consultations of medical specialists, such as psychiatrists or urologists, are important. However, most participants said that it wasn't easy to find specialists for regular consultations within the $\mathrm{NH}$.

No other long-term care home believes us when I tell them that we have a neurologist who comes to see our residents regularly. That's not something you see very often. (Focus group 1)

\section{Extended availability}

The extended availability of GPs during the evening hours was received very differently among participants. Whilst being accessible even in the evening was natural for some GPs, others refused to do it due to the high workload.

In some NHs with extended GP hours, GPs and nurses had the agreement to call the GP first in case of need. Together with the nursing staff they would then decide what to do next. Again, one of the participants indicated that this new course of action had already helped prevent hospitalizations. 
However, all participants agreed that to ensure extended accessibility, more GPs would be needed to distribute the workload better.

There is always someone to approach and we agreed that we would be called before an ambulance is requested. We then come around and have a look, if that is really necessary." (Focus group 1)

\section{Case conferences, quarterly and yearly meetings}

Case conferences as well as quarterly and yearly meetings had not yet been implemented in most $\mathrm{NHs}$. Most participants struggled to distinguish between the three kinds of meetings. One participant mentioned that they had been conducting quarterly talks within the framework of the regular medical rounds.

"So the medical rounds usually take a long time and the quarterly talk is supposed to be 90 minutes I think. I think we do that several times per quarter during the medical rounds, right?" (Focus group 4)

\section{Standard courses of treatment}

When asked about the standard courses of treatment, opinions differed between participants. For some participants, the standard courses of treatment were too detailed to learn and follow. Also, some participants did not know that the pathways were available as hard copy outside the CCC.

Other participants thought the standard courses of treatment were helpful, noticing that it made GPs mindful of previously overlooked issues. Especially the treatment pathway for the transition from curative to palliative care was mentioned to be particularly helpful. One participant reported that the standard courses of treatment were used as a template for further developments of other pathways, such as a procedure for urinary tract infections. Participants also appreciated the training given before the implementation of the standard courses of treatment.

"I thought the training was interesting, there were examples and categories: the agitated patient, the aggressive patient. That is extremely helpful, because it actually is a simple pattern, giving you a structure for problem solving." (Focus group 10)

\section{Overall assessment}

The overall assessment differed among participants. Some participants regarded the project as "genius", improving the care of residents in NHs. Due to the additional compensation; the GPs said they were in a good position to implement all aspects of CoCare. A special focus was put on the preventative aspect of CoCare, making it easier to treat residents' illnesses early. However, some participants stated that most aspects of CoCare already were the standard care in their respective $\mathrm{NH}$. Some participants feared that if CoCare were implemented in standard care, it would be a bureaucratic hurdle. 
"Of course, we want CoCare to be evaluated positively, because the system itself is genius and it would be a pity if it would not be part of the standard care in future." (Focus group 7)

\section{Discussion}

Results from the focus groups show that the project implementation is complex, and some modules were easier to implement or more important to some participants than to others. The overall acceptance of the project was good. However, some participants feared that the implementation in standard care because of the complexity and bureaucracy.

Pertinent German organizations recommend using tools like regularly scheduled medical rounds or extended availability to help improve interprofessional communication. Furthermore, nursing staff play a crucial role as they are the ones organizing interprofessional medical care in long-term care homes (22). CoCare combines all these tools, providing a solid framework to facilitate interprofessional communication. It is therefore not surprising that interprofessional communication was seen as one of the most important modules of the project, with CoCare being perceived as a team building intervention. Participants in our study valued the newly built teams of GPs and the contact persons within NHs. The implementation of a fixed contact person was not seen as useful in a previous qualitative study assessing interprofessional collaboration in nursing homes in Germany (23). However, the authors noted that the lack of perceived usefulness was due to $\mathrm{NHs}$ already having a fixed contact person for GPs before the intervention (23). Thus, it can be hypothesized that a fixed contact person is perceived as useful when newly implemented in a $\mathrm{NH}$.

Overall, interprofessional collaboration and communication was found to have an impact on health outcomes $(24,25)$. For the elderly, interprofessional collaboration has positive effects on things like quality of life, mortality or length of stay in hospitals (26). Furthermore, there is some evidence that interprofessional collaboration is cost saving (27). Some participants in this study had already concluded that the improved collaboration and communication prevented unnecessary hospital admissions and therefore had an impact on health outcomes for residents.

Even though the overall acceptance of the project was found to be good, some barriers for implementation were reported by the participants. Participants mentioned that the project was complex and too detailed. For example, the purpose of case conferences, quarterly and yearly meetings could not be distinguished by some participants and therefore were not implemented in some $\mathrm{NHs}$. In a scoping review, the intervention complexity was a common barrier for the implementation of integrated care (28), with rising complexity making it more difficult to implement the intervention (29).

Furthermore, the intervention was perceived as too bureaucratic by some participants who worried the implementation into standard care, especially as understaffing was seen as the biggest barrier for implementation. Previous reports found that staff would work overtime to compensate understaffing and bureaucracy (29). Even tough participants in this study did not mention overtime the issue of 
understaffing and overtime is well known in Germany with an average of 42 hours of overtime per nurse within six months (30).

All barriers reported by the participants are well known (28) and implementation of complex health intervention remains a challenge (31).Implementation of health services interventions, particularly complex ones, requires countless organizational and individual change processes (29). Completing these processes takes at least one year, most likely longer (32). With a project length of 42 months, CoCare provides a good time frame for full implementation and normalization. Furthermore, the project compensates higher workload for NHs and GPs and some barriers, such as the double documentation, will dissolve after implementation into regular care.

\section{Strength And Limitations}

With $\mathrm{N}=11$ focus group interviews and a total of $\mathrm{N}=74$ participants, this qualitative study compromises a relatively big sample size. Although generalizability cannot be reached with a qualitative study design, this study adheres to recommendations for the guidelines for the process evaluation of complex interventions (16).

Nonetheless, this design shows some limitations. First of all, results were not distinguished between professionals. However, doctors are known to evaluate collaboration and communication better than nursing staff within $\mathrm{NHs}$ (33-35). As the aim of this study was to analyze the overall acceptance and implementation, we decided not to distinguish between professions. Furthermore, as a modular interview guideline was used, not every focus group talked about every topic in detail. However, results show a good overview of acceptance and barriers perceived.

\section{Conclusion}

The results shown in this study are promising, with participants reporting a positive impact on health outcomes and a good acceptance of the intervention. Especially collaboration and communication seem to have improved. However, a final conclusion can only be drawn after the summative evaluation has been completed. The quantitative evaluation will be primarily based on claims data and questionnaires and focus on the number of hospitalizations, quality of life of residents and costs. Based on the results of this study, positive results of the summative evaluation are expected.

\section{List Of Abbreviations}

$\mathrm{NH}=$ Nursing Home

GP = General practitioner

CoCare $=$ Coordinate Medical Care 
CCC $=$ CoCare Cockpit (electronic medical record)

\section{Declarations}

\section{Ethical approval and consent to participate}

Ethics Approval of this study was granted by the ethics committee at the Chamber of Physicians of the State of Baden-Württemberg (Reference number: B-F-2017-127; 14.11.2017) as well as by the ethics committee at the University of Freiburg Medical Centre (Reference number: 333/17; 03.08.2017). Written informed consent of each participant was obtained.

\section{Consent for publication}

Not applicable

\section{Availability of data and materials}

The datasets analyzed during the current study are not publicly available due to data protection regulations.

\section{Funding}

This research was funded by the Innovation Committee at the Federal Joint Committee (G-BA), Germany under grant number NVF1_2016-080. The article processing charge was funded by the BadenWuerttemberg Ministry of Science, Research and Art and University of Freiburg in the funding programme Open Access Publishing.

\section{Competing interest}

The authors declare that they have no competing interests

\section{Consent for publication}

All authors have approved the final version of the manuscript.

\section{Authors' contributions}

Data collection was performed by $\mathrm{CR}$ and BB. Data preparation and analysis were performed by RvdW and VK. EF did conceptualize the study and supervised all steps. The first draft of the manuscript was written by RvdW and all authors commented on previous versions of the manuscript. All authors read and approved the final manuscript.

\section{Acknowledgements}

Not applicable 


\section{References}

1. Statistische Ämter des Bundes und der Länder. Demografischer Wandel in Deutschland - Bevölkerungsund Haushaltsentwicklung im Bund und in den Ländern. Wiesbaden: Statistische Ämter des Bundes und der Länder; 2011.

2. Isfort M, Rottländer R, Weidner F, Gehlen D, Hylla J, Tucman D. Pflege-Thermometer 2018. Eine bundesweite Befragung von Leistungskräften zur Situation der Pflege und Patientenversorgung in der stationären Langzeitplfege in Deutschland. Pflegeforschung DIfa, editor. Köln: Deutsches Insitut für angewandte Pflegeforschung; 2018.

3. van der Zee J, Kroneman M. A promising approach in comparative research on care for the elderly. BMC Med. 2011;9:124-.

4. Glynn LG, Valderas JM, Healy P, Burke E, Newell J, Gillespie P, et al. The prevalence of multimorbidity in primary care and its effect on health care utilization and cost. Family practice. 2011;28(5):516-23.

5. van den Bussche H, Schön G, Kolonko T, Hansen H, Wegscheider K, Glaeske G, et al. Patterns of ambulatory medical care utilization in elderly patients with special reference to chronic diseases and multimorbidity--results from a claims data based observational study in Germany. BMC geriatrics. 2011;11:54.

6. Schulz M, Czwikla J, Tsiasioti C, Schwinger A, Gand D, Schmiemann G, et al. Differences in medical specialist utilization among older people in need of long-term care - results from German health claims data. Int J Equity Health. 2020;19(1):22-.

7. Balzer Z, Butz S, Bentzel J, D. B, D. L. Beschreibung und Bewertung der fachärztlichen Versorgung von Pflegeheimbewohnern in Deutschland. Schriftenreihe Health Technol Assess. 2013;125(348).

8. Manckoundia P, Menu D, Turcu A, Honnart D, Rossignol S, Alixant J-C, et al. Analysis of Inappropriate Admissions of Residents of Medicalized Nursing Homes to Emergency Departments: A Prospective Multicenter Study in Burgundy. J Am Med Dir Assoc. 2016;17(7):671.e1-.e6717.

9. Lemoyne SE, Herbots HH, De Blick D, Remmen R, Monsieurs KG, Van Bogaert P. Appropriateness of transferring nursing home residents to emergency departments: a systematic review. BMC geriatrics. 2019;19(1):17.

10. Björck $\mathrm{M}$, Wijk $\mathrm{H}$. Is hospitalisation necessary? A survey of frail older persons with cognitive impairment transferred from nursing homes to the emergency department. Scand J Caring Sci. 2018;32(3):1138-47.

11. Rocha JVM, Marques AP, Moita B, Santana R. Direct and lost productivity costs associated with avoidable hospital admissions. BMC Health Services Research. 2020;20(1):210. 
12. Dwyer R, Gabbe B, Stoelwinder JU, Lowthian J. A systematic review of outcomes following emergency transfer to hospital for residents of aged care facilities. Age and ageing. 2014;43(6):759-66.

13. Kessler C, Williams MC, Moustoukas JN, Pappas C. Transitions of care for the geriatric patient in the emergency department. Clinics in geriatric medicine. 2013;29(1):49-69.

14. Giger $M$, Voneschen N, Brunkert T, Zúñiga F. Care workers' view on factors leading to unplanned hospitalizations of nursing home residents: A cross-sectional multicenter study. Geriatric Nursing. 2019.

15. Brühmann BA, Reese C, Kaier K, Ott M, Maurer C, Kunert S, et al. A complex health services intervention to improve medical care in long-term care homes: study protocol of the controlled coordinated medical care (CoCare) study. BMC Health Services Research. 2019;19(1):332.

16. Moore GF, Audrey S, Barker M, Bond L, Bonell C, Hardeman W, et al. Process evaluation of complex interventions: Medical Research Council guidance. BMJ (Clinical research ed). 2015;350:h1258.

17. Carroll C, Patterson M, Wood S, Booth A, Rick J, Balain S. A conceptual framework for implementation fidelity. Implementation science : IS. 2007;2:40.

18. Montgomery P, Underhill K, Gardner F, Operario D, Mayo-Wilson E. The Oxford Implementation Index: a new tool for incorporating implementation data into systematic reviews and meta-analyses. Journal of clinical epidemiology. 2013;66(8):874-82.

19. Tong A, Sainsbury P, Craig J. Consolidated criteria for reporting qualitative research (COREQ): a 32item checklist for interviews and focus groups. International Journal for Quality in Health Care. 2007;19(6):349-57.

20. Mayring P. Qualitative Inhaltsanalyse. Grundlagen und Techniken. 7 ed. Weinheim: Deutscher Studienverlag; 2000.

21. VERBI Software. MAXQDA - Software für qualitative Datenanaylse, 1989 - 2019. Berlin, Germany: VERBI Software; 2019.

22. Diakonisches Werk der Evangelischen Kirche in Deutschland e.V. Ärztliche Versorgung im Pfelgeheim. . Handreichung. Stuttgart2007.

23. Müller CA, Fleischmann N, Cavazzini C, Heim S, Seide S, Geister C, et al. Interprofessional collaboration in nursing homes (interprof): development and piloting of measures to improve interprofessional collaboration and communication: a qualitative multicentre study. BMC Fam Pract. 2018;19(1):14.

24. Martin JS, Ummenhofer W, Manser T, Spirig R. Interprofessional collaboration among nurses and physicians: making a difference in patient outcome. Swiss medical weekly. 2010;140:w13062. 
25. Reeves S, Pelone F, Harrison R, Goldman J, Zwarenstein M. Interprofessional collaboration to improve professional practice and healthcare outcomes. Cochrane Database Syst Rev. 2017;6(6):Cd000072.

26. Tsakitzidis G, Timmermans O, Callewaert N, Verhoeven V, Lopez-Hartmann M, Truijen S, et al. Outcome Indicators on Interprofessional Collaboration Interventions for Elderly. International journal of integrated care. 2016;16(2):5.

27. Counsell SR, Callahan CM, Tu W, Stump TE, Arling GW. Cost Analysis of the Geriatric Resources for Assessment and Care of Elders Care Management Intervention. J Am Geriatr Soc. 2009;57(8):1420-6.

28. Threapleton DE, Chung RY, Wong SYS, Wong E, Chau P, Woo J, et al. Integrated care for older populations and its implementation facilitators and barriers: A rapid scoping review. International Journal for Quality in Health Care. 2017;29(3):327-34.

29. Ling T, Brereton L, Conklin A, Newbould J, Roland M. Barriers and facilitators to integrating care: experiences from the English Integrated Care Pilots. International journal of integrated care. 2012;12:e129.

30. Isfort M, Weidner F, Neuhaus A, Kraus S, Köster V-H, Gehlen D. Pflege-Thermometer 2009. Köln: Deutsches Insitut für angewandte Pflegeforschung e.V.; 2010.

31. Aasmul I, Husebo BS, Flo E. Description of an advance care planning intervention in nursing homes: outcomes of the process evaluation. BMC geriatrics. 2018;18(1):26.

32. Shaw S, Levenson R. Towards integrated care in Trafford. Nuffield Trust; 2011.

33. Reese C, Brühmann BA, Farin E. Wie beurteilen Pflegekräfte und Ärzte die interprofessionelle Zusammenarbeit in Pflegeeinrichtungen? 18 Deutscher Kongress für Versorgungsforschung (DKVF); Berlin. Düsseldorf: German Medical Science GMS Publishing House; 2019.

34. Meyer-Kühling I, Schröder J, Frankenberg C. Erwartungshaltungen, Kommunikation und Kooperation von Pflegenden und Ärzten in der stationären Altenpflege. HeilberufeScience. 2015;6(3):70-5.

35. O'Leary KJ, Ritter CD, Wheeler H, Szekendi MK, Brinton TS, Williams MV. Teamwork on inpatient medical units: assessing attitudes and barriers. Quality \& safety in health care. 2010;19(2):117-21.

\section{Figures}




\begin{tabular}{|c|c|}
\hline CoCare Cockpit (CCC) & - Computerized documentation system, provided to the NHs and GPs \\
\hline General pracitioner Team & $\begin{array}{l}\text { - A team of GPS provides primary care to NH residents } \\
\text { - Patients are assigned to their chosen GP, GPs may treat any patient on behalf of another GP }\end{array}$ \\
\hline Medical rounds & $\begin{array}{l}\text {-Weekly on-site medical rounds with GPS and nursing staff } \\
\text { - Regular rounds by medical specialists, such as psychiatrists } \\
\text { - A portable sonography device is provided to every NH }\end{array}$ \\
\hline Medication checks & -Medication plans are written by GPS and regulary monitored \\
\hline $\begin{array}{l}\text { Communication \& collaboration } \\
\text { between doctors and nursing staff }\end{array}$ & $\begin{array}{l}\text { - Cocare contact person in every NH } \\
\text { - Standards and structured processes are implemented, describing workflows for unplanned } \\
\text { cases }\end{array}$ \\
\hline Extended availability & - GPS can be reached by phone after office hours until 9 p.m. \\
\hline Case conferences & $\begin{array}{l}\text { - Case conferences, quarterly and yearly meetings are held between GPs and nursing staff to } \\
\text { discuss difficult cases }\end{array}$ \\
\hline Standard courses of treatment & $\begin{array}{l}\text { - Treatment procedures (e.g., urinary tract infections) are provided, involving all specialists, } \\
\text { GPs and nursing staff }\end{array}$ \\
\hline
\end{tabular}

\section{Figure 1}

Overview of all aspects of the CoCare Intervention

\section{Supplementary Files}

This is a list of supplementary files associated with this preprint. Click to download.

- AdditionalFile1 InterviewguidelineCoCare.pdf

- AdditionalFile2Codingsystem.pdf 